Klein PD $1983{ }^{13} \mathrm{C}$-bicarbonate kinetics and ${ }^{13} \mathrm{C}$-lysine oxidation in normal, postpartum and lactating women. Clin Res 31:625A

22. Hock R 1968 Energy metabolism in mammals. In: Altman P, Dittner D (eds) Metabolism. Federation American Society for Experimental Biology, Bethesda, MD, pp 249-350

23. Slanger $\mathrm{BH}$, Kusubov N, Winchell HS 1970 Effect of exercise on human $\mathrm{CO}_{2}$ $\mathrm{HCO}^{-}$kinetics. J Nucl Med 11:716-718.

24. Irving CS, Wong WW, Shulman RJ, Smith O, Klein PD $1983^{13}[\mathrm{C}]$ bicarbonate kinetics in humans: Intra-vs interindividual variations. Am $J$ Physiol 245:R190-R202

25. Yang RD, Irving CS, Wong WW, Hoffer JH, Young VR, Klein PD 1983 The effect of diet and meal ingestion on whole body ${ }^{13} \mathrm{C}$ bicarbonate kinetics in young men. Fed Proc 42:825A

26. Irving CS, Lifschitz CH, Wong WW, Nichols BL, Klein PD 1983 Bicarbonate/ $\mathrm{CO}_{2}$ pool sizes and flux in infants measured by $\mathrm{NaH}^{13} \mathrm{CO}_{3}$ tests. Pediatr Res 17:1225A

\title{
Electrodermal Potential and Conductance Measurements Clinically Discriminate between Cystic Fibrosis and Control Patients
}

\author{
PAUL S. WILLIAMSON, DON C. FOWLES, AND MILES WEINBERGER \\ Department of Family Practice, The University of Iowa College of Medicine, Department of Psychology, The \\ University of Iowa, and Department of Pediatrics, The University of Iowa Hospitals and Clinics, \\ Iowa City, Iowa 52242
}

\begin{abstract}
To evaluate the adaptation of electrodermal techniques for cystic fibrosis screening, skin surface bioelectric measurements were recorded from 37 established cystic fibrosis patients, 45 asthmatic patients, and 10 normal controls, ranging in age from 6 to $22 \mathrm{yr}$. Six skin potential and six skin conductance measures of sweat gland activity without the collection of sweat distinguished between the cystic fibrosis, normal, and asthmatic groups ( $F$ ratios $>10.0 ; p<0.0001)$. Discriminant analysis using the two best electrodermal measures (the mean of five preresponse potential levels and the mean of five preresponse conductance levels for each subject) to assign experimental group membership matched actual group membership with $92.7 \%$ accuracy. We believe these results warrant further investigation of electrodermal procedures as a direct, simple, yet noninvasive means of screening for cystic fibrosis. (Pediatr Res 19: 810-814, 1985)
\end{abstract}

\section{Abbreviations}

SPL, skin potential level

SCL, skin conductance level

SPR, skin potential response

SCR, skin conductance response

The Gibson-Cooke iontophoretic sweat chloride test (1) remains the standard for the laboratory diagnosis of cystic fibrosis, under optimal conditions yielding $1.3 \%$ false-positives and $4.5 \%$ false-negatives (2). Since this test is not suitable for general screening nor useful for neonates, we became interested in trans-

Received December 10, 1984; accepted March 14, 1985.

Address reprint requests and correspondence to Paul S. Williamson, M.D., Department of Family Practice, The University of lowa College of Medicine, Iowa City, IA 52242

Supported in part by a grant from the Cystic Fibrosis Foundation. epidermal skin potential and skin conductance bioelectric measurements for the clinical purpose of preliminary cystic fibrosis screening. These electrodermal measurements, which are relatively simple to obtain, are sensitive to sweat gland activity in amounts too small to produce surface sweating (3-8). These microdischarges of sweat transiently alter the standing electric SPL and SCL, producing a SPR and a SPR (see Figs. 1 and 2). The eccrine sweat glands in palmar and plantar skin are activated by a range of sensory, emotional, and physiologic (e.g. deep breaths) stimuli, facilitating noninvasive assessment.

The well-known increase in sweat sodium chloride in cystic fibrosis is accompanied by a less well-known increase in sweat ductal lumen negativity relative to interstitial fluid. Maximally stimulated individual sweat tubules generate a greater lumen negative bioelectric potential relative to interstitial fluid in cystic fibrosis patients (9). Consistent with the hypothesis of reduced permeability to the reabsorption of chloride (9), nasal epithelium from cystic fibrosis polyps has a higher electrical resistance than normal turbinate epithelium (10).

Our purpose was to evaluate the validity of discriminating between cystic fibrosis patients and asthmatic or normal controls by means of transepidermal skin surface bioelectric recordings in a pediatric clinical setting. In addition to the measurement of SPL with activated sweat glands, which is most comparable to previous reports of greater lumen negativity, new dimensions are added by the assessment of SPRs and of both SCLs and SCRs. SCL and SCR were expected to be influenced by the higher salt content of cystic sweat, which should promote greater conductance via both the sweat gland and the nonsudorific pathways through the epidermis.

\section{METHODS}

Subjects. Electrodermal measures were recorded from 114 patients including 50 cystic fibrosis patients, 54 asthmatic patients, and 10 normal controls between 4 and $22 \mathrm{yr}$ of age. The mean value of previously collected sweat tests for 37 cystic 


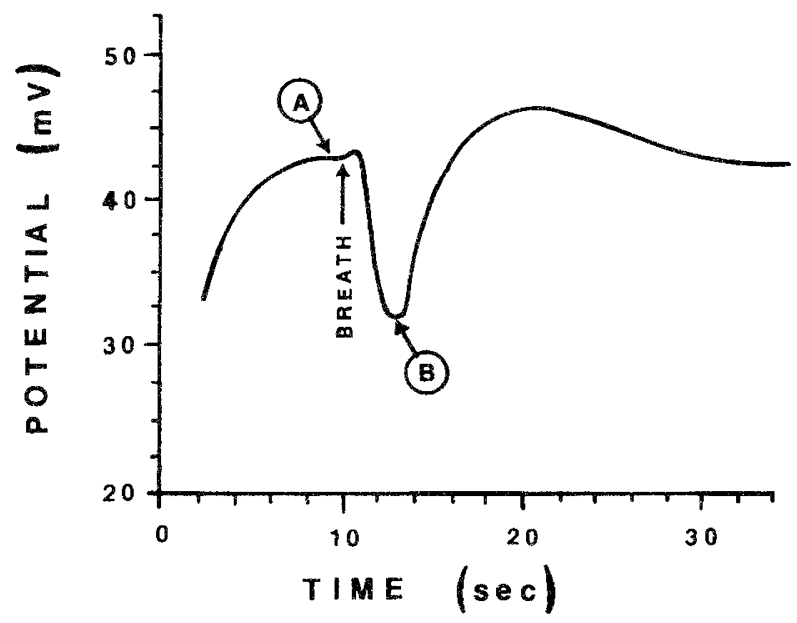

Fig. 1. Standard positive potential response (SPR) to a breath, recorded with negative up. $A$ is the level of surface negativity just prior to a positive response (no. 3, Table 1). The response amplitude (nos. 4, 5, 6 in Table 1 ) is point $A$ minus point $B$.

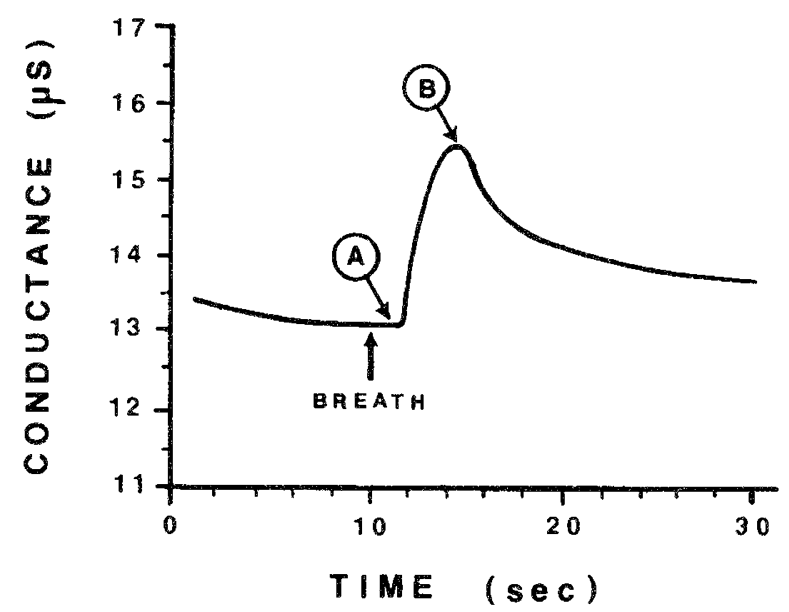

Fig. 2. Standard SCR to a breath. $A$ is the preresponse level (no. 9, Table 2). The response amplitude (nos. 10 and 11 in Table 2) is point $B$ minus point $A$. All values have been converted to a standard surface area and reported as microsiemens per $\mathrm{cm}^{2}$ in Table 2 .

fibrosis patients was $101.7 \mathrm{mEq} /$ liter (range 71 to 220 ) and for the 17 asthmatic patients for whom results were available was $15.2 \mathrm{mEq} /$ liter (range 4.4 to 33.5 ). Six subjects' electrodermal data were difficult to interpret due to technical difficulties, and all ten 4- and 5-yr-old subjects (seven cystic fibrosis and three asthma) were excluded from the primary analysis because some were unable to follow all the instructions. In addition, six subjects were not included in the analysis because of low effort in the series of fast, deep breaths employed to induce palmar sweat gland responses. "Low effort" was operationally defined as skin conductance responses which were less than $30 \%$ of the maximum conductance response elicited by the balloon pop-startle stimulus described below. Therefore, satisfactory recordings for 92 subjects were included in the primary analysis- 37 cystic fibrosis patients, 45 asthmatic patients, and 10 normal controls.

Medication. Because some medications may alter sweat gland functioning, an attempt was made to record subjects in as drugfree a state as possible. However, since 12 cystic fibrosis patients and 38 asthmatic patients required adrenergic, theophylline, and steroid medication, the data from these subjects were compared to those of the drug-free subjects in the statistical analysis.

Procedure. After cleaning the skin with isopropyl alcohol and air-drying, Beckman silver/silver chloride electrodes (contact area $=0.636 \mathrm{~cm}^{2}$ ) were applied to the palmar surface of the fingers. For measures of potential, a sandpaper-abraded reference site $3 \mathrm{~cm}$ distal to the olecranon along the ulna was used (11), with the active electrode being placed on the palmar surface of the distal middle phalanx of the hand. The contact medium for potential measures was $0.05 \mathrm{M}$ sodium chloride in a mixture of $50 \%$ Unibase (a cold cream base marketed by Parke-Davis) and $50 \%$ polyethylene glycol (mol wt 400 to 600 ), to keep the stratum corneum minimally hydrated $(12,13)$. For skin conductance measures, $0.5 \mathrm{~V}$ was applied in conjunction with a Wheatstone Bridge circuit to the palmar surface of two adjacent distal phalanges via a medium consisting of $0.05 \mathrm{M}$ sodium chloride in a Unibase-water mixture, and the conductance was measured as the voltage across a small resistor in series with the skin (14). Two direct current low voltage channels of a Grass model 7 polygraph recorded the skin potential and skin conductance tracings simultaneously for one series of stimuli given to each subject.

After the leads were attached, the presence of an intact circuit was verified by having subjects take a fast, deep breath. This physiologic stimulus reliably elicits a sweat gland response in palmar and plantar skin, and was used as a baseline test response. Next, a 10-min rest period allowed the electrolyte-skin interface to reach an approximate equilibrium at minimum standing levels. The instruction that the rest period was over produced a gradual increase in both the potential (i.e. greater surface negativity) and conductance levels over $30 \mathrm{~s}$, associated with the sweat gland response to this stimulus. When the levels stabilized at the higher level, a series of stimuli were presented by asking for fast, deep breaths. Each breath simultaneously produced a large SCR and a large positive-going (i.e. decreased negativity) SPR on the tracing (Figs. 1 and 2). These breaths were spaced judiciously to coincide with the peak of the recovery from the previous SPR, following a procedure designed to produce large positive SPRs $(15,16)$. The deep breaths were requested until five clear positive SPRs were obtained and until exhorting the subject to take faster, deeper breaths or startling him/her by clapped hands elicited only smaller responses.

Because of the possibility that adequate responses would not be elicited if patients failed to take deep enough breaths (i.e. showed too little effort), a startle response was also elicited by asking patients to blow up a balloon (with eyes closed) until it popped unexpectedly. As noted above, six patients were excluded from the analysis for giving "low effort breaths."

Electrodermal measures. The potential measures scored from the polygraph record in millivolts (always negative at the palm relative to the abraded reference site), included: 1) the minimum standing potential level reached during the rest period ("minimum level" in Table 1);2) the largest negative value for the preresponse levels; 3 ) the mean of the five potential levels just prior to the five largest positive-going skin potential responses (an estimate of the skin potential level during this period of repeated responding); 4) the largest breath-induced positive SPR obtained during the series; 5 ) the mean of the five largest positive SPRs; and 6) the positive amplitude (SPR) of the balloon-startle response.

The conductance measures (Table 2), scored in microsiemens per $\mathrm{cm}^{2}$, included: 7) the minimum conductance level, or highest resistance, developed by the skin with resting sweat glands; 8) the maximum skin conductance, or lowest resistance, in the record; 9) the mean of five conductance levels just prior to the five largest SCRs; 10) the largest breath-induced SCR; 11) the mean of the five largest breath-induced SCRs; and 12) the amplitude (SCR) of the balloon-startle response.

\section{RESULTS}

All 12 of the electrodermal measures shown in Tables 1 and 2 distinguished between the normal or asthmatic control groups and the cystic fibrosis patients (F ratios $>10.0 ; p<0.0001$ ). The 
Table 1. Mean value of potential measures comparing cystic fibrosis, asthmatic, and normal subjects

\begin{tabular}{|c|c|c|c|c|c|}
\hline \multirow[b]{2}{*}{ Variable } & \multirow[b]{2}{*}{ Group } & \multirow[b]{2}{*}{ Mean (S.D.) $\mathrm{mV}$} & \multicolumn{2}{|c|}{$\begin{array}{l}t \text { test statistic comparing two } \\
\text { groups* }^{*}\end{array}$} & \multirow{2}{*}{$\begin{array}{c}\text { Overall } \\
\text { F ratioł } \\
\text { for ANOVA } \\
\text { comparing } \\
\text { three groups }\end{array}$} \\
\hline & & & $\begin{array}{c}\text { Cystic } \\
\text { vs. } \\
\text { asthmatic }\end{array}$ & $\begin{array}{c}\text { Cystic } \\
v s . \\
\text { normal }\end{array}$ & \\
\hline 1. Minimum level & $\begin{array}{l}\text { Cystic } \\
\text { Asthma } \\
\text { Normal }\end{array}$ & $\begin{array}{l}-31.5(13.5) \\
-20.5(8.8) \\
-17.4(10.0)\end{array}$ & 4.2 & $\begin{array}{l}3.1 \\
(0.002)\end{array}$ & 12.4 \\
\hline $\begin{array}{l}\text { 2. Largest preresponse } \\
\text { level }\end{array}$ & $\begin{array}{l}\text { Cystic } \\
\text { Asthma } \\
\text { Normal }\end{array}$ & $\begin{array}{l}-67.7(7.3) \\
-49.6(9.1) \\
-50.6(8.2)\end{array}$ & 9.7 & 6.4 & 50.4 \\
\hline $\begin{array}{l}\text { 3. Mean of } 5 \text { prere- } \\
\text { sponse levels }\end{array}$ & $\begin{array}{l}\text { Cystic } \\
\text { Asthma } \\
\text { Normal }\end{array}$ & $\begin{array}{l}-62.6(7.9) \\
-41.8(9.2) \\
-43.2(8.7)\end{array}$ & 10.8 & 6.8 & 62.2 \\
\hline $\begin{array}{l}\text { 4. Maximum response } \\
\text { amplitude }\end{array}$ & $\begin{array}{l}\text { Cystic } \\
\text { Asthma } \\
\text { Normal }\end{array}$ & $\begin{array}{l}22.1(6.5) \\
14.2(6.2) \\
16.9(8.8)\end{array}$ & 5.6 & $\begin{array}{l}1.8 \\
\text { (NS) }\end{array}$ & 14.4 \\
\hline $\begin{array}{l}\text { 5. Mean of } 5 \text { largest re- } \\
\text { sponses }\end{array}$ & $\begin{array}{l}\text { Cystic } \\
\text { Asthma } \\
\text { Normal }\end{array}$ & $\begin{array}{l}17.5(5.7) \\
10.7(5.6) \\
13.0(7.3)\end{array}$ & 5.4 & $\begin{array}{l}2.1 \\
(0.05)\end{array}$ & 13.9 \\
\hline $\begin{array}{l}\text { 6. Amplitude of balloon } \\
\text { response }\end{array}$ & $\begin{array}{l}\text { Cystic } \\
\text { Asthma } \\
\text { Normal }\end{array}$ & $\begin{array}{l}25.2(9.2) \\
15.9(7.9) \\
21.8(13.9)\end{array}$ & 4.9 & $\begin{array}{l}0.9 \\
(\mathrm{NS})\end{array}$ & 10.5 \\
\hline
\end{tabular}

* Significant at $p<0.0001$, unless specified in parentheses.

$\dagger$ All are significant at $p<0.0001, \mathrm{df}=2,89$.

Table 2. Mean value of conductance measures comparing cystic fibrosis, asthmatic, and normal subjects

\begin{tabular}{|c|c|c|c|c|c|}
\hline \multirow[b]{2}{*}{ Variable } & \multirow[b]{2}{*}{ Group } & \multirow[b]{2}{*}{ Mean (SD) $\mu \mathrm{s} / \mathrm{cm}^{2}$} & \multicolumn{2}{|c|}{$\begin{array}{l}t \text { test statistic comparing two } \\
\text { groups* }\end{array}$} & \multirow{2}{*}{$\begin{array}{c}\text { Overall } \\
\text { F ratio } \\
\text { for ANOVA } \\
\text { comparing } \\
\text { three groups }\end{array}$} \\
\hline & & & $\begin{array}{c}\text { Cystic } \\
\text { vs. } \\
\text { asthmatic }\end{array}$ & $\begin{array}{l}\text { Cystic } \\
\text { vs. } \\
\text { normal }\end{array}$ & \\
\hline 7. Minimum level & $\begin{array}{l}\text { Cystic } \\
\text { Asthma } \\
\text { Normal }\end{array}$ & $\begin{array}{c}15.9(15.4) \\
5.3(4.2) \\
6.2(6.3)\end{array}$ & $\begin{array}{l}4.1 \\
(0.0002)\end{array}$ & $\begin{array}{l}3.0 \\
(0.005)\end{array}$ & 11.1 \\
\hline $\begin{array}{l}\text { 8. Largest preresponse } \\
\text { level }\end{array}$ & $\begin{array}{l}\text { Cystic } \\
\text { Asthma } \\
\text { Normal }\end{array}$ & $\begin{array}{l}43.9(24.8) \\
18.1(10.5) \\
23.5(12.3)\end{array}$ & 5.9 & $\begin{array}{l}3.6 \\
(0.001)\end{array}$ & 21.8 \\
\hline $\begin{array}{l}\text { 9. Mean of } 5 \text { prere- } \\
\text { sponse levels }\end{array}$ & $\begin{array}{l}\text { Cystic } \\
\text { Asthma } \\
\text { Normal }\end{array}$ & $\begin{array}{l}31.5(21.5) \\
12.7(7.3) \\
15.8(9.2)\end{array}$ & 5.1 & $\begin{array}{l}3.4 \\
(0.001)\end{array}$ & 16.8 \\
\hline $\begin{array}{l}\text { 10. Maximum response } \\
\text { amplitude }\end{array}$ & $\begin{array}{l}\text { Cystic } \\
\text { Asthma } \\
\text { Normal }\end{array}$ & $\begin{array}{l}5.4(2.8) \\
2.5(1.5) \\
3.4(2.4)\end{array}$ & 5.8 & $\begin{array}{l}2.1 \\
(0.05)\end{array}$ & 18.2 \\
\hline $\begin{array}{l}\text { 11. Mean of } 5 \text { largest re- } \\
\text { sponses }\end{array}$ & $\begin{array}{l}\text { Cystic } \\
\text { Asthma } \\
\text { Normal }\end{array}$ & $\begin{array}{l}4.4(2.4) \\
2.1(1.3) \\
2.6(1.7)\end{array}$ & 5.4 & $\begin{array}{l}2.2 \\
(0.05)\end{array}$ & 16.8 \\
\hline $\begin{array}{l}\text { 12. Amplitude of balloon } \\
\text { response }\end{array}$ & $\begin{array}{l}\text { Cystic } \\
\text { Asthma } \\
\text { Normal }\end{array}$ & $\begin{array}{l}9.7(6.5) \\
3.8(2.9) \\
6.2(5.9)\end{array}$ & 5.1 & $\begin{array}{l}1.6 \\
\text { (NS) }\end{array}$ & 14.5 \\
\hline
\end{tabular}

* Significant at $p<0.0001$, unless specified in parentheses.

+ All are significant at $p<0.0001, \mathrm{df}=2,89$.

cystic fibrosis patients showed more surface negative skin potential levels (variables 1 to 3 ) and larger positive SPRs (variables 4 to 6) than did the control groups. Similarly, higher (tonic) skin conductance levels (variables 7 to 9) and larger (phasic) skin conductance responses (variables 10 to 12 ) were seen in cystic fibrosis patients than in normal or asthmatic controls. All $t$ test comparisons were significant except those for cystics and normals for variables 4,6 , and 12 .

The ability of electrodermal measures to discriminate between groups was examined further by stepwise multiple regression to 
determine the best one-, two-, and three-variable discriminations between the cystic fibrosis and asthmatic groups. As expected from the $t$ test, the mean preresponse potential level (no. 3 in Table 1) provided the best one-variable discrimination, accounting for $60 \%$ of the diagnostic variance $\left(\mathrm{R}^{2}=0.600\right)$. The twovariable model consisting of the mean preresponse potential level and the mean preresponse conductance level (no. 9 in Table 2) produced an $\mathrm{R}^{2}$ of 0.667 . Adding the best third variable to create a three-variable model only increased the $R^{2}$ by 0.019 . Thus, a two-variable model seems most appropriate.

A visual representation of the separation between the two groups by the above two-variable model, mean potential level plotted against mean conductance level, is shown in Figure 3. Cystic fibrosis patients tend to have higher levels of both standing potential and conductance than do controls and fall in the upper right portion of the graph, while asthmatic controls fall into the lower left portion.

Analysis for confounding factors. There were no differences within the 12 electrodermal variables when males were compared to females. A tendency toward higher conductance levels in younger cystic fibrosis subjects was not significant. When the electrodermal measures of the sweat-tested asthmatic controls were compared, there were no indications that an occult cystic was missed in the asthmatic control group.

Analysis of variance was used to determine whether medication influenced the electrodermal measures. Within the cystic fibrosis group, three medication classes were identified: 24 subjects were drug free, nine subjects were taking an adrenergic, and three were taking both an adrenergic and theophylline. There were four medication classes within the asthmatic group: six subjects were drug free, 19 were taking theophylline, 15 were taking an adrenergic and theophylline, and four were taking an adrenergic, theophylline, and a steroid. Both analyses did not show a statistically significant difference between drug classes for any of the 12 electrodermal variables.

Discriminant analysis. The best two-variable prediction model (using the mean of five preresponse potential levels and the mean of five preconductance levels) was used to reassign the 82 individual patients to the cystic fibrosis or asthmatic groups with the

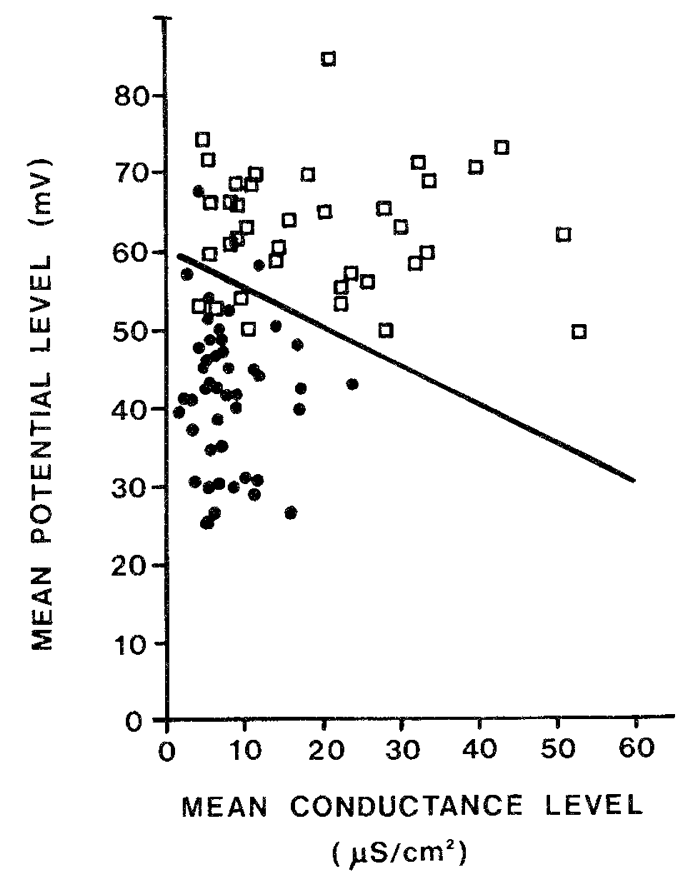

Fig. 3. Separation of cystic fibrosis patients $(\square, n=37)$ and asthmatic controls $(-n=45)$ by plotting the mean of five preresponse potential levels against the mean of five preresponse conductance levels for each individual. Four cystic fibrosis subject points and two asthmatic points
Table 3. Classification matrix for reassignment of group membership for 82 subjects based on mean of five preresponse potential levels and 5 preresponse conductance levels, $92.7 \%$ correctly classified

\begin{tabular}{ccc}
\hline & \multicolumn{2}{c}{ Predicted group } \\
\cline { 2 - 3 } Actual group & $\begin{array}{c}\text { No. (\%) } \\
\text { cystic fibrosis }\end{array}$ & $\begin{array}{c}\text { No. (\%) } \\
\text { asthmatic }\end{array}$ \\
\hline Cystic fibrosis patients & $33(89 \%)$ & $4(11 \%)$ \\
Asthmatic controls & $2(4 \%)$ & $43(96 \%)$ \\
\hline
\end{tabular}

discriminant program of the Statistical Package for the Social Sciences. This assignment matched the actual group membership with $92.7 \%$ accuracy (see Table 3 for the classification matrix). Thirty-three of 37 cystic fibrosis patients were correctly regrouped. Four were incorrectly reassigned as asthmatics, an $11 \%$ false-negative rate. Forty-three of the 45 asthmatics were correctly reassigned, a $4 \%$ false-positive rate.

\section{DISCUSSION}

Electrodermal measurements do not distinguish between normals and asthmatics, nor do they distinguish the heterozygote carriers of the cystic fibrosis gene (Fowles DC, unpublished data). However, they do compare favorably with the laboratory data obtained previously by Knowles et al. $(10,17)$ and by Quinton and Bijaman (9) for distinguishing between cystics and noncystics. Even though the sweat gland response to our series of breath stimuli could conceivably vary from subject to subject for psychological reasons, the largest preresponse level generated by stimulated sweat glands $(-62.6 \pm 7.9 \mathrm{mV})$ agrees very closely with the nasal epithelium-flux chamber preparation maximum level $(-53.0 \pm 1.8 \mathrm{mV})$ and the iontophoretically stimulated individual sweat droplet maximum potential level $(-66.3 \pm 2.1$ $\mathrm{mV}$ ) for cystic fibrosis patients. Some of the variance can be explained by the inverse relationship between the potential level and the sweat rate, for which we did not control (18).

The minimum potential levels of Quinton and Bijamin (9) did not distinguish between groups, while there was an apparent difference in minimum SPLs in our subjects. There is probably no difference between groups with empty sweat glands. However, under the test conditions of this study, our pediatric patients were not able to adequately "rest." Hence, their sweat glands were probably not generating truly minimum levels.

Our results showed higher conductance in cystic fibrosis patients rather than the lower conductance previously reported by Knowles et al. (10). This is because the factors involved in transepidermal conductance with eccrine sweat glands are different from those involved in mucous membrane conductance. With active sweat glands, the major contributor to palmar skin conductance is the salt bridge formed by sweat-filled ducts as they pass through the more resistant stratum corneum. The higher salt content of cystic sweat would conduct current even more readily. It is also possible that the stratum corneum has a higher salt content in cystic fibrosis and that this nonsudorific pathway becomes more conductive as a result.

With regard to the question of which of these 12 variables provided the best discrimination between groups, several considerations point to the mean preresponse potential level. First, at a theoretic level this measure yields the best estimate of the lumen-negative sweat gland sodium reabsorption potential, being obtained 1) when the sweat ducts are full and thus carry the ductal potential to the skin surface (i.e. there is a smaller voltage loss between the duct and the skin surface because of the lowered resistance associated with the duct filling) (12), and 2) when ductal sodium reabsorption is fully activated by duct filling. Second, the mean preresponse skin potential level yielded the largest $F$ ratio in the comparison of the three groups (Table 1). 
Third, it also yielded the largest $t$ test value in the cystic-asthmatic comparisons and again in the cystic-normal comparisons.

Discriminant analysis with inclusion of all 114 patients in which measurements were attempted ( 50 cystic fibrosis patients, 54 asthmatics, and 10 controls) did not substantially increase the percentage of false-positives $(6.3 \%)$ although more cystic fibrosis patients were missed $(22 \%)$.

It would simplify clinical procedures to use only the potential or only the conductance measures to distinguish between groups, since only one hand would be recorded and scored. However, subject reclassification by discriminant analysis utilizing only the six potential or the six conductance measures lowered the accuracy of correct reclassification to $86 \%$ for potential and $77 \%$ for conductance measures, which indicates that both systems may need to be measured.

This first electrodermal study of an older pediatric population has demonstrated that a simplified, clinical technique has the potential for accurately discriminating between normal, asthmatic, and cystic fibrosis patients possibly without large applied currents or the use of drugs to stimulate sweating.

Acknowledgments. The authors are indebted to Nolan Donovan Evans, R.N., for technical assistance in data collection and to our most cooperative pediatric volunteers. We thank Jean Koviach, R.N., for clinical assistance at The University of Iowa Cystic Fibrosis Center, David Wall for assistance in processing data, and Dr. Kenzo Sato for reviewing the manuscript.

\section{REFERENCES}

1. Gibson L, Cooke R 1959 A test for concentration of electrolytes in sweat in cystic fibrosis of the pancreas utilizing pilocarpine by iontophoresis. Pediatrics 23:545-549

2. di Sant'Agnese PA, Gibson LE 1962. The eccrine sweat defect in cystic fibrosis of the pancreas (mucoviscidosis). Adv Biol Skin 3:229-255

3. Fowles D 1974 Mechanisms of electrodermal activity. In: Thompson RF, Patterson M (eds) Bioelectric Recording Techniques. Part C: Receptor and Effector Processes. Academic Press, New York, pp 231-271

4. Fowles D. The eccrine system and electrodermal activity. In: Coles MGH, Porges SW, Donchin E, (eds) Psychophysiology: Systems, Processes, and Applications, Vol 1. Guilford Press, New York (in press)

5. Edelberg R 1972 The electrodermal system. In: Greenfield NS, Sternbach RA, (eds) Handbook of Psychophysiology. Holt, Rinehart and Winston, New York, pp 367-418

6. Edelberg R 1971 Electrical properties of the skin. In: Elden HR (ed) A Treatise of Skin, Vol 1. Biophysical Properties of the Skin. Wiley-Interscience, New York, 513-550

7. Adams T 1966 Characteristics of eccrine sweat gland activity in the footpad of the cat. J Appl Physiol 21:1004-1012

8. Stombaugh DP, Adams T 1971 Skin electrical phenomena, sweat gland activity, and epidermal hydration of the cat foodpad. Am J Physiol 221:10141018

9. Quinton PM, Bijman J 1983 Higher bioelectric potentials due to decreased chloride absorption in the sweat glands of patients with cystic fibrosis. $\mathrm{N}$ Engl J Med 308:1185-1189

10. Knowles MR, Stutts MJ, Spock A, Fischer N, Gatzy JT, Boucher RC 1983 Abnormal ion permeation through cystic fibrosis respiratory epithelium. Science 221:1067-1070

11. Edelberg R 1967 Electrical properties of the skin. In: Brown CC (ed) Methods in Psychophysiology. Williams \& Wilkins Company, Baltimore, pp 1-53

12. Edelberg R 1968 Biopotentials from the skin surface: the hydration effect. Ann NY Acad Sci 148:252-262

13. Schneider RE, Fowles D 1978 A convenient, non-hydrating electrolyte medium for the measurement of electrodermal activity. Psychophysiology 15:483486

14. Fowles D, Christie M, Edelberg R, Grings W, Lykken D, Venables P 1981 Publication recommendations for electrodermal measurements. Psychophysiology 18:232-239

15. Fowles D, Rosenberry R 1973 Effects of epidermal hydration on skin potential responses and levels. Psychophysiology 10:601

16. Fowles D, Schneider RE 1978 Electrolyte medium effects on measurements of palmar skin potential. Psychophysiology 15:474-482

17. Knowles M, Gatzy J, Boucher R 1981 Increased bioelectric potential difference across respiratory epithelia in cystic fibrosis. N Engl J Med 305:1489-1495

18. Bijman J, Quinton PM 1984 Influence of abnormal Cl impermeability on sweating in cystic fibrosis. Am J Physiol 247:C3-C9 